\title{
NATIONAL NEWSLETTER
}

\author{
Editor: NORMAN GREEN \\ Assistant Editors: HARLAN C. CREIGHTON / MARIE FIDLER / E. R. SEAQUIST \\ Please submit all material and send all communications to the address below:
}

The Editor, Newsletter, McLaughlin Planetarium, 100 Queen's Park, Toronto, Ontario

\section{Announcement of Symposium}

Section III (Science) of the Royal Society of Canada is to hold a Symposium "Chemical Evolution in the Universe" during the annual meeting of the Society at Queen's University, Kingston, Ontario, this coming summer. The Symposium will take place between 9:00 a.m. and noon on Wednesday, June 6, 1973, with the following four invited speakers as participants:

DR. RICHARD L. SEARS University of Michigan

The Origin of the Chemical Elements and Stellar Evolution

DR. BARRYE. TURNER National Radio Astronomy Observatory, Greenbank, W. Virginia

Interstellar Molecules

DR. PETER M. MILlMAN, F.R.S.C. National Research Council of Canada

Interplanetary Material

DR. DAVID W. STRANGWAY University of Toronto

The Moon

The talks will be addressed to an audience of scientists in general. Anyone interested is invited to attend. Further details, such as the exact location of the meeting, can be obtained nearer the time from

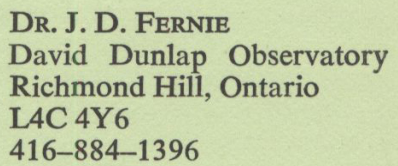

\section{Meeting of SCITEC}

SCITEC (The Association of the Scientific, Engineering, \& Technological Community of Canada) will hold its Fifth Annual Conference and Business Meeting on May 3rd-4th, 1973, at McGill University, Montreal.

The general theme of the conference will be: PRIORITIES IN SCIENCE AND TECHNOLOGY FOR CANADA.

Emphasis will be placed on Natural and Human Resources, with special emphasis on Energy, Population Growth, and Regional Disparities.

The conference will conclude by establishing Priorities for the Scientific Societies and SCITEC.

\section{The Teaching of Astronomy}

I am about to embark on a survey of the teaching of astronomy in the elementary and secondary schools in Canada. I want to find the answers to such questions as (1) what astronomy is taught in what grades of what schools; (2) how does astronomy fit into the science curriculum as a whole; (3) to what extent is astronomy an optional part of the science curriculum; (4) what training and preparation do teachers have for the teaching of astronomy; and (5) what methods, aids and books are used in the teaching of astronomy? From these answers, I want to find out what professional and amateur astronomers can best do to promote and improve the teaching of astronomy in the schools. 